\title{
Exercício da autonomia sobre o próprio corpo e a vida a partir das concepções de Kant e Stuart Mill: fundamentos para a definição de limites terapêuticos em testamento vital
}

\author{
Exercise of legal autonomy of the person's own body and life in the light of Kant \\ and Stuart Mill's conceptions: fundamentals for the definition of therapeutic limits \\ in vital will
}

\author{
Andrea Aldrovandi* \\ Maria Claudia Crespo Brauner ${ }^{*}$
}

\section{Resumo}

Esta pesquisa objetiva analisar os fundamentos da autonomia sobre o próprio corpo e vida a partir de uma abordagem das concepções de autonomia de Kant e Stuart Mill. Para tanto, faz-se uma análise comparativa entre as ideias dos referidos autores, visando a realçar as restrições que cada uma das teorias prescreve às decisões voltadas à própria vida. Ao examinar as diferentes concepções, o estudo reflete sobre o testamento vital e a possibilidade que esse documento confere ao próprio paciente terminal de decidir antecipadamente sobre os tratamentos médicos e os limites terapêuticos que interferem no processo vital. Através dessa análise, conclui-se que o testamento vital é um importante instrumento para o exercício da autonomia irrestrita do indivíduo sobre si mesmo, defendida por Mill, pois permite a decisão do indivíduo sobre a sua própria vida. O exercício da autonomia pressupõe a liberdade de escolha entre as opções possíveis e a capacidade para avaliação dos riscos e das consequências da decisão. Assim, o testamento vital exalta o respeito à dignidade do paciente, independente da sua condição, até o final da vida.

Palavras-chave: Autonomia. Kant. Stuart Mill. Testamento vital.

\section{Abstract}

The main objective of this research is to analyze the background of the autonomy of individual's own body and life, considering Kant and Stuart Mill's perspective. Thus, we compare the ideas of these authors, in order to highlight the limits that each theory has related to the decision of individual's life. Examining the different conceptions, we reflect upon the vital will and the possibility that, with this document, a terminal patient can previously decide about medical treatment as well as the therapeutic limits, which interfere in the vital process. Therefore, we conclude that the vital will is an important tool to the individual's unrestricted autonomy exercise about him/herself, suggested by Mill, since it allows the person to decide about his/her own life. The autonomy exercise presupposes freedom to choose different possible options and the ability to evaluate the risks and the consequences of these decisions. Thus, the vital will spotlights the respect to the patient's dignity, regardless his/her condition, until the end of his/her life.

Keywords: Autonomy. Kant. Stuart Mill. Vital will.

\section{Introdução}

O ser humano é livre para decidir sobre suas ações e, no exercício dessa liberdade, vivencia constantes conflitos entre os impulsos e a razão. O poder de agir segundo o próprio querer (ou dever) denomina-se autonomia.

Doutora em Direito (UNISINOS). Mestre em Direito (UCS). Professora do Curso de Graduação em Direito da Universidade de Caxias do Sul. Especialista em Direito de Família e Sucessões. Advogada. Caxias do Sul - RS - Brasil. Brasil. E-mail: andrea@martiniadvogados.com.br.

Doutora em Direito pela Université de Rennes1/ França. Professora da Universidade Federal do Rio Grande/ FURG. Coordenadora do Mestrado em Direito e Justiça Social da FURG. Pesquisadora Produtividade do CNPq. Coordenadora do Grupo de Pesquisa e Direito e Justiça Social. Caxias do Sul - RS - Brasil. E-mail: mclaudia.brauner@uol.com.br. 
Autônomo é aquele que determina a própria lei. A autonomia pode sofrer influências diversas, as ações podem ser movidas por impulsos, desejos ou pela razão, mas é o homem que decide como agir.

Essa autonomia é reconhecida ao homem, em razão de sua dignidade e racionalidade, pois possui capacidade para avaliar as consequências da sua conduta. Limitar a autonomia é violar a dignidade humana, contudo a liberdade de decisão sobre as ações humanas não pode ser entendida como absoluta. Dependendo do fundamento das ações, a ação poderá ser considerada boa em si, dentro da moralidade, ou não.

A ação humana pode ser direcionada a outra pessoa, ou referir-se ao próprio corpo e à própria vida. Nas ações que atingem terceiros, os limites são mais claros, enquanto que nas ações direcionadas a própria pessoa, o debate é mais delicado.

Assim, o objetivo do presente artigo é refletir sobre os limites ao exercício da autonomia nas ações do indivíduo sobre si mesmo, que hoje, no Brasil, pode ser determinado por um instrumento denominado testamento vital. Essa análise é feita a partir de uma abordagem genérica sobre o conteúdo e a noção de autonomia no contexto atual.

Para esse fim, primeiramente é feita uma comparação entre a concepção de autonomia de Kant e de Stuart Mill. Esta comparação entre as teorias citadas permite analisar se podem ser adotadas hoje sem limites, ou ajustes, como embasamento de possíveis soluções aos polêmicos desafios bioéticos que discutem o direito de decidir sobre a própria morte.

Questiona-se: Existem limites para o exercício desse direito, ou se o homem, como "soberano", possui poderes ilimitados, inclusive sobre a própria vida? E, se existem limites, como devem ser determinados? Será que a autonomia invocada na atualidade para justificar determinadas condutas poderia estar fundamentada nas concepções citadas?

Para buscar as respostas para essas questões, apresenta-se uma breve evolução da noção de autonomia e as diferentes visões e conceitos sobre o termo, desde a época antiga até a atualidade. Faz-se, após um breve relato sobre o pensamento de Kant, o contexto no qual o filósofo desenvolveu a autonomia kantiana e os pontos principais ressaltados nas suas principais publicações. Da mesma forma, é destacado o pensamento de Stuart Mill e os principais argumentos que fundamentam o seu pensamento sobre a autonomia.

Posteriormente, as ideias de Kant e Mill são comparadas e analisadas, oportunidade em que são evidenciadas as influências e insuficiências de cada teoria para a leitura atual da autonomia, tal como ela é tratada nas discussões bioéticas que tratam dos eventuais limites das ações do indivíduo sobre si mesmo. Ao final, analisa-se o conceito e a finalidade do testamento vital, cujo fundamento principal reside justamente na autonomia e na dignidade da pessoa.

\section{A evolução do conceito de autonomia}

A autonomia é um termo de origem grega, formada por autos (próprio, eu) e nomos (regra, domínio, governo, lei). Em sentido amplo, pode significar autogoverno, liberdade de direitos e escolha, e de agir conforme a própria vontade (COHEN; MARCOLINO, 2002, p. 85).

$\mathrm{Na}$ Antiguidade, a definição apresentava conotação política. Pelos gregos, a autonomia era considerada liberdade interna ou legislação própria (NOUR, 2009, p. 76). Nessa época, Platão desenvolveu um conceito mais complexo, que incluía a suficiência econômica. A concepção de Platão, apresentada em "A República", acabou contribuindo para a concepção moderna de autonomia. Para Platão, a razão governa os bons, os maus são dominados pelos desejos (TAYLOR, 2011, p. 155). Em sua obra, Platão defende que o homem bom possui autodomínio, é senhor de si mesmo, é racional, e isso acontece quando a parte superior da alma consegue dominar a parte inferior da alma, permitindo uma visão correta e clara das coisas (TAYLOR, 2011, p. 155-157). 
Aristóteles, contudo, apresentou outra noção. Para o filósofo, a autonomia está relacionada com a virtude, que é voluntária. A virtude é consistente em uma mediania, que é determinada por um princípio racional próprio do homem dotado de sabedoria prática (phrónimos). Assim, o homem é responsável pela sua disposição de caráter, pois os vícios também são voluntários. Depende do homem a prática de atos nobres ou vis, por isso, depende do homem ser virtuoso ou vicioso. As virtudes são destruídas pelo excesso ou pela deficiência, e preservadas pela mediania. Os limites não são delimitados facilmente, nem impostos a priori, pois a decisão depende da percepção de quem vai decidir (ARISTÓTELES, 2009).

$\mathrm{Na}$ Idade Média, destacam-se as ideias de Santo Agostinho sobre o "livre-arbítrio", ou seja, a possibilidade de escolher fazer o bem (TAYLOR, 2011, p. 169-190). Essas ideias foram desenvolvidas sobre a noção platônica, e são apontadas como uma das fontes da autonomia (GARRAFA, 2012). Nessa fase, a autonomia tomou um sentido religioso: representava liberdade de crença e de consciência (NOUR, 2009, p. 76).

Essa ideia de livre-arbítrio, baseada na religião, foi destruída por Kant (1724-1804), por sua concepção da autonomia fundada na razão (HABERMAS, 2004, p. 147). A partir de Kant, a autonomia adquiriu um sentido universal, absorvido por diversas ciências. Kant concebeu a autonomia como "a possibilidade de o ser humano se determinar como ser racional” (NOUR, 2009, p. 77). Segundo essa concepção, o homem é guiado pela razão, ele é o legislador que comanda a si próprio seguindo os mandamentos da razão, e não outras inclinações externas.

Ainda outras concepções surgiram com o tempo. Entre elas, o pensamento de John Stuart Mill (1806-1873), que influenciou uma das concepções atuais sobre autonomia individual, a de que o indivíduo é soberano sobre si mesmo, seu corpo e sua mente.

Nessa análise evolutiva sobre o conceito de autonomia, destacam-se duas das concepções, frequentemente invocadas nas discussões bioéticas, que questionam os limites de ação do homem sobre o próprio corpo e a própria vida: a autonomia segundo Kant e a autonomia segundo Mill.

\section{Autonomia kantiana}

Influenciado pelo ceticismo de David Hume (1711-1776), especialmente pelas críticas filosóficas à Religião e à Teologia, Kant desenvolveu sua teoria, e assim revolucionou a filosofia, defendendo o homem como um ser livre e autônomo, emancipado dos valores exteriores, que deve agir conforme a própria razão.

Em Crítica da razão pura (1781), Kant desenvolve a doutrina de autolegislação da razão, posteriormente denominada de autonomia (NOUR, 2009, p. 77). Por sua tese, é a razão que fornece as leis pragmáticas da livre conduta do homem, cujo fim é dado a priori. É a razão que comanda de modo absoluto, com uma função reguladora, que serve para efetuar a unidade de leis empíricas, unificando os fins, e fixando um fim único, a felicidade (KANT, 2004, p. 568).

Kant "utiliza o conceito de autonomia como autodeterminação da razão prática, que pressupõe a autodeterminação da razão teórica" (NOUR, 2009, p. 77). Para o filósofo, autonomia da vontade é a faculdade de se autolegislar. "É a autonomia que explica por que o homem deve se sujeitar à lei moral: a lei moral obriga porque é produzida pelo próprio agente, enquanto autônomo." (NOUR, 2009, p. 77).

Kant (1781) denomina essa independência a toda causalidade de 'liberdade transcendental'. Assim, a moralidade tem sua origem no sentido mais estrito da liberdade, o sentido transcendental (HÖFFE, 2005, p. 219).

Essa concepção revela-se na ética prática como autodeterminação. Portanto, a revolução causada por Kant em Crítica da razão pura, que liberta a razão teórica das influências exteriores (dos impulsos e da própria religião), é a base para o desenvolvimento da filosofia prática, apresentada posteriormente, na qual a autonomia revela-se como determinante para a realização de ações classificadas como boas, ou morais. 
Nessa fase, Kant, que antes reconheceu ter sido despertado "de sua sonolência dogmática" pela obra de Hume, e que confessou que foi Hume "que o levou a fazer investigações que culminaram na Crítica da Razão Pura", afasta-se da influência desse filósofo.

Nesse sentido, Chaves (2012) explica que "o problema básico da filosofia moral de Kant pode ser visto como uma tentativa consciente de responder às conclusões céticas e 'irracionalistas' de Hume, a respeito da moralidade".

Isto porque Hume tentou demonstrar que a razão não pode ser o motivo de nossas ações, e que estas são movidas pelas paixões. Assim, ao defender que a razão não pode mover nossas ações, Hume excluiu a moralidade da esfera da razão e 'excluiu a razão pura de toda e qualquer participação na vida moral'.

Por tudo isso, Chaves (2012) entende que a Crítica da razão prática (1788) foi escrita para demonstrar os erros desse entendimento humeano.

Na filosofia prática, foi Jean-Jacques Rousseau (1712-1778) que influenciou o pensamento filosófico e moral kantiano (BARRETTO, 2010, p. 32). Segundo Höffe (2005, p. 216), a noção de autonomia como autolegislação remete a obra de Rousseau, quando este refere que "a obediência a uma lei dada por si mesmo é liberdade". Ou seja, só age livremente aquele que determina a própria lei que deve seguir.

Alguns trechos da obra $O$ contrato social (1762) demonstram essa influência. Um exemplo pode ser destacado do Capítulo VIII, em que Rousseau refere que a passagem do estado natural ao estado civil imprimiu moralidade às ações humanas, assim, a voz do dever fez com que "o homem, que até então só tinha olhado para si mesmo, se visse forçado a agir por meio de outros princípios e a consultar a razão antes de seguir seus pendores" (ROUSSEAU, s.d., p. 32).

Dessa forma, o homem que se priva da liberdade natural, para submeter-se aos limites da vontade geral, perde várias vantagens da natureza, mas ganha outras maiores: "suas faculdades se exercitam e desenvolvem, suas ideias se ampliam, seus sentimentos se enobrecem", e o homem transforma-se, de um "animal estúpido e limitado" a um "ser inteligente", "um homem" (ROUSSEAU, s.d., p. 32).

Sem aprofundar o sentido filosófico do termo liberdade, por não ser seu objetivo, Rousseau (s.d., p. 33) refere-se à liberdade moral como "a única que torna o homem senhor de si mesmo". Contudo, Barretto (2010, p. 40) ressalta que, "enquanto a liberdade, no pensamento rousseauniano, encontra-se no corpo político, Kant sustenta que ela se realiza neste corpo, mas como expressão da autonomia individual"."

Kant procurou em Rousseau a inspiração para os fundamentos de uma ética válida universalmente (BARRETO, 2010, 40-41). Para tanto, Kant, ao contrário de Rousseau, que ficou prisioneiro do empirismo, e fundamentou suas ideias no amor por si próprio (HÖFFE, 2005, p. 222), buscou a base no princípio supremo da moralidade, o imperativo categórico.

Em Fundamentação à metafísica dos costumes (1785), Kant desenvolve o fundamento da moralidade, que só pode ser investigado pela filosofia pura, a priori, na razão. Para Kant o fundamento da moralidade não pode ser abstraído do empírico, mas sim de regras universais que determinam o conceito de dever. A razão é ordenadora do agir humano.

Explica que uma boa ação, ou boa vontade, é boa em si mesma, e não pelo que promove, ou para alcançar outro fim (KANT, 2004, p. 22). A conduta, para ser boa, deve ser praticada por dever. A ação é necessária por respeito à lei universal. Esse mandamento da razão se funde com a vontade como princípio, determinando as boas ações. O mandamento nunca será efeito da ação, mas de um princípio, uma causa.

Quando a lei universal é o fundamento, a causa ou princípio da ação, da vontade, isso constitui o bem denominado por Kant como moral. O valor moral, que determina as boas ações, existe a priori, na

No contexto do conceito de autonomia, Kant irá absorver os conceitos de vontade e lei. De Rousseau, Kant absorveu a ideia de que existe "uma natureza do homem escondido no fundo da pluralidade das formas humanas manifestadas, e suas leis" (BARRETTO, 2010, p. 40). 
razão. A razão cobra o respeito à lei universal. Só age moralmente, ou pratica uma ação boa em si, aquele que respeita a prescrição universal que existe para todo ser racional. Não age assim aquele que pratica algo por temor a consequências prejudiciais ou visando a outro fim (KANT, 2004, p. 30).

A moralidade decorre da ação que segue o imperativo categórico, mandamento absoluto e necessário que fundamenta a ação boa em si mesma. Boa é a ação determinada pela razão, não por causas subjetivas, mas objetivas. Por princípios que são válidos a todo o ser racional (KANT, 2004, p. 44-45), o que se difere do imperativo hipotético, que diz que "uma ação é boa e vista de algum propósito possível ou real".

O dever de agir moralmente é uma necessidade incondicionada e que vale para todos. Exprime-se em imperativo categórico, que contém a legislação universal válida a qualquer ser racional. O imperativo categórico (mandamento moral) ordena que o homem haja em obediência à máxima de uma vontade universalmente legisladora.

O imperativo categórico é descrito da seguinte forma "age só segundo a máxima tal que possas ao mesmo tempo querer que ela se torne lei universal” (KANT, 2004, p. 51). Essa universalidade considera, segundo Kant, a natureza, resultando dessa constatação o imperativo universal do dever: "age como se a máxima da tua ação devesse se tornar, pela tua vontade, lei universal da natureza" (KANT, 2004, p. 52).

Uma das situações analisadas sob esta máxima diz respeito ao suicídio. Kant questiona se, em razão das adversidades, aquele que se desapegou da vida poderia, racionalmente, por amor de si mesmo, atentar contra a própria vida. Será que esta máxima poderia servir universalmente, tornando-se lei universal da natureza?

A resposta de Kant $(2004$, p. 52) é negativa, pois tal máxima não poderia ser considerada lei da natureza, uma vez que ela mesma seria contraditória: "se vê que uma natureza cuja lei fosse destruir a vida em virtude do mesmo sentimento cuja determinação é suscitar a sua conservação se contradiria a si mesma, e não existiria como natureza". Portanto, para Kant, essa lei é contrária ao princípio supremo de todo o dever.

O princípio do amor a si mesmo, ou da conveniência própria, garante o bem-estar, mas não é justo. Nesses casos, a vontade é afetada pela inclinação. O princípio subjetivo do desejar é impulso (KANT, 2004, p. 53-58).

O homem está sujeito à sua própria legislação (embora universal). A razão serve à vontade como princípio da autodeterminação da vontade, determinando o fim que deve ser considerado em suas ações. O homem é um fim em si mesmo, é isso fundamenta a dignidade humana. Nesse sentido, todo o ser racional "[...] existe como fim, e não apenas como meio para o uso arbitrário desta ou daquela vontade. Em todas as suas ações, pelo contrário, tanto nas direcionadas a ele mesmo, como nas que são a outros seres racionais, deve ser ele sempre considerado simultaneamente como fim" (KANT, 2004, p. 58).

Assim, como fim prático supremo e imperativo categórico, no que diz respeito à vontade humana, Kant (2004, p. 59) afirma que "aquilo que é um fim para todos, é um fim em si mesmo", podendo servir como lei prática universal, que determina: "age de tal maneira que possa usar a humanidade, tanto em tua pessoa como na pessoa de qualquer outro, sempre e simultaneamente como fim e nunca simplesmente como meio" (KANT, 2004, p. 59).

A liberdade deve ser atribuída a todos os seres racionais, decorre do reconhecimento da dignidade, e deve ser verificada a priori. A liberdade de vontade é autonomia. Portanto, a autonomia kantiana não é incondicional, pois passa por "um critério de universalidade" (GOLDIM, 2012).

Segundo esse princípio, o homem que pensa em suicidar-se indagará se a sua ação estará de acordo com a ideia de humanidade como um fim em si mesma. "Se, para fugir de uma situação penosa, se destrói a si mesmo, serve-se ele de uma pessoa como simples meio para conversar até o fim da vida 
uma situação tolerável" (KANT, 2004, p. 60). Mas o homem não é uma coisa, um objeto passível de ser utilizado como simples meio (KANT, 2004, p. 60).

Por tudo isso, conclui-se que "o princípio da autonomia da vontade consiste na sujeição do homem à lei moral, o que o torna livre na medida em que se submete à sua lei própria, no entanto universal" (BARRETTO, 2010, p. 41). O princípio da autonomia tem, assim, "a pretensão de formular normas válidas e necessárias universalmente" (BARRETTO, 2010, p. 41).

\section{A concepção de autonomia de Stuart Mill}

O britânico John Stuart Mill (1806-1873) é conhecido como um dos maiores pensadores liberais de todos os tempos. Em sua obra Sobre a liberdade (1859), Mill defende a individualidade e a autonomia diante da sociedade e do Estado, e impõe como único limite ao exercício da autonomia o respeito ao semelhante. Por consequência, as ações do homem, direcionadas a si próprio, não encontrarão limites segundo a tese de Mill. Pelo contrário, essas ações são justificadas pela dignidade que lhe é reconhecida.

A teoria individualista de Mill tem como preocupação maior o bem-estar do indivíduo, a maximização do bem-estar e a qualidade de vida. Gaille (2010, p. 46, tradução livre), explica que o liberalismo político e moral, formulado por Stuart Mill na metade do século XIX, parece ser a expressão filosófica de certa tendência a fazer do indivíduo o único juiz de sua vida. ${ }^{2}$

As decisões do homem não são limitadas por regras morais válidas universalmente, mas simplesmente pela vontade daquele que decide, e desde que suas ações não prejudiquem os outros. "A liberdade do indivíduo deve ser limitada dessa maneira, ele não deve se tornar a si mesmo um problema para as outras pessoas" (MILL, 2011, p. 114). Nessa visão, a vida de um indivíduo só pode ser avaliada por ele mesmo ${ }^{3}$ (GAILLE, 2010, p. 47, tradução livre).

Contra a ideia de uma felicidade coletiva e de uma instância habilitada a definir uma norma utilitária válida para todos os membros da sociedade, Mill ressaltou a tensão sempre possível entre felicidade individual e felicidade coletiva, e defendeu a tese segundo a qual cada ser humano é irredutível a qualquer outro. Gaille (2010, p. 46-47, tradução livre) comenta que Mill critica a tendência que nós todos temos de querer impor uma norma aos outros e julgar a vida do outro em função de nossas próprias opções morais. ${ }^{4}$

Vale dizer: na concepção de Mill (2011, p. 114), as ações consideradas boas e morais não seguem regras estabelecidas a priori, pelo contrário, são tomadas com base na experiência do homem, na sua vivência, só assim poderá ele decidir de acordo com suas preferências, pois, "[...] seria absurdo pretender que as pessoas devem viver como se nada tivesse sido conhecido no mundo antes de aparecerem nele; é como se a experiência nunca tivesse mostrado que um modo de existência ou conduta é preferível a outro".

Para Mill (2011, p. 117), o homem, como ser racional, é capaz de usar e interpretar sua experiência à sua maneira, e assim decidir sobre suas ações. Optar "é um privilégio do ser humano [...]. Cabe a ele descobrir qual parte da experiência recolhida é aplicável às suas próprias circunstâncias e caráter".

\footnotetext{
2 "Le libéralisme politique et moral formulé par J. S. Mill au milieu du XIX siècle apparaît être l'expression philosophique de cette tendance à faire de l'individu le seul juge de sa vie [...]' (GAILLE, 2010, p. 46).

3 “Contre l'idée d'un bonheur collectif et celle d'une instance habilitée à definir une norme d'utilité valable por tous les membres de la société, J. S. Mill a souligné la tension toujours possible entre bonheur individuel et bonheur collectif et a défendu la thèse selon laquelle chaque être humain est irréductible à tout autre. II a critiqué la tendance que nous avons tous à vouloir imposer une norme à autrui et à juger sa vie en fonction de nos propres options morales" (GAILLE, 2010, p. 47).

4 "Contre l'idée d'un bonheur collectif et celle d'une instance habilitée à definir une norme d'utilité valable por tous les membres de la société, J. S. Mill a souligné la tension toujours possible entre bonheur individuel et bonheur collectif et a défendu la thèse selon laquelle chaque être humain est irréductible à tout autre. Il a critiqué la tendance que nous avons tous à vouloir imposer une norme à autrui et à juger sa vie en fonction de nos propres options morales" (GAILLE, 2010, p. 47).
} 
Considerando que o ser humano também é social, o próprio autor questiona: "Quanto da vida humana deve caber na individualidade e quanto na sociedade? Qual seria o justo limite do indivíduo sobre si mesmo? (MILL, 2011, p. 141).

Essa liberdade de agir segundo a própria vontade sofre limitações quando a ação atinge terceiros. Mill (2011, p. 141) defende que, na conduta do homem com os outros, algumas regras devem ser observadas para que "as pessoas possam saber o que esperar". Nesses casos, o respeito ao outro é um limitador do exercício da autonomia na teoria de Mill, "mas em relação ao que importa a cada pessoa, à sua individualidade espontânea deve-se permitir um exercício livre" (MILL, 2011, p. 144).

$\mathrm{Na}$ percepção milleana as faculdades humanas da percepção, do juízo, do discernimento, da atividade mental e até mesmo da preferência moral exercem-se apenas quando se faz uma escolha. Aquele que age apenas segundo o costume não faz nenhuma escolha, e não conquista nenhuma prática quer para discernir, quer para desejar o que é melhor. Quem escolhe para si próprio plano emprega todas as suas faculdades e constrói seu próprio mundo.

Refletindo a teoria milleana, Simões (2007, p. 139) deduz que pode ser razoável e muito melhor para os indivíduos livres pôr fim à sua vida, porque, de uma parte, o bem que ela possuía já não tinha qualquer valor, por outro lado, esse bem é insignificante em comparação com o sofrimento que deve suportar antes que ele (o bem) inevitavelmente chegue. Ele destaca que um mal incurável de um doente poderia levar a pensar que o fato de ele ser livre não reduz as penas e os sofrimentos que sua doença lhe inflige. Se a liberdade tem sentido, é esse poder de escolha entre escolher continuar vivendo em sofrimento e pôr fim à sua vida.

No pensamento moral e político, Mill demonstra que os homens são o que podem ser. O que Mill considera como mais fundamental na natureza humana é a possibilidade de escolha e, correlativamente, a possibilidade de ser diferente. Sendo assim, segundo Mill, uma das características mais importantes da excelência humana é sua individualidade, ou sua capacidade de ser autônomo (SIMÕES, 2007, p. 59).

\section{Os limites ao exercício da autonomia nas concepções de Kant e Mill}

As duas teorias referidas (teoria deontológica de Kant e teoria utilitarista de Stuart Mill) são invocadas atualmente nos debates sobre os limites do exercício da autonomia, principalmente nas ações direcionadas à própria pessoa.

Toda pessoa é livre para decidir sobre a sua vida, mas a decisão pode ser influenciada por diversos fatores. Questiona-se se existe um limite justo para a restrição ao exercício da autonomia, ou seja, o que justificaria a imposição de limites ao exercício da autonomia à pessoa consciente, responsável e capaz para decidir?

Pode-se afirmar que o princípio do respeito à autonomia da pessoa, invocado na bioética, encontra fundamento na dignidade humana a partir das ideias de Kant, e na concepção de autonomia de Mill. Nesse sentido, afirmam Cohen e Marcolino (2002, p. 87) que, apesar das diferenças - o ponto de vista de Stuart Mill requer uma não influência na expressão da autonomia do indivíduo; e o de Kant estabelece uma moral imperativa para moldar certas atitudes a respeito do indivíduo -, ao final, essas filosofias são, uma e outra, invocadas em um suporte do princípio de respeito pela autonomia.

Isso porque a autonomia está diretamente ligada à dignidade da pessoa, o que, por consequência, leva ao reconhecimento de que o indivíduo é capaz de deliberar e de agir na direção dessa deliberação, conforme defende Kant. Rohden (2005, p. 22) explica a atualidade do conceito kantiano:

A filosofia moral de Kant é uma ética do indivíduo responsável perante todos os outros. O que nela está em jogo é o amor de cada um pelos outros na mesma medida do seu amor a si mesmo. Seu objeto é a humanidade. A teoria ética kantiana é, mediante conceitos, como autonomia, universalidade e justificação racional, a base indispensável do pensamento ético contemporâneo. 
Assim, o respeito à autonomia exige que se resguarde o objetivo do paciente, pois "rejeitar os objetivos e julgamentos pessoais ou restringir a liberdade de agir de acordo com os seus próprios objetivos e julgamentos é falhar no respeito à autonomia" (COHEN; MARCOLINO, 2002, p. 87).

Mas também porque o respeito à autonomia significa hoje "valorizar a consideração sobre as opiniões e escolhas, evitando, da mesma forma, a obstrução de suas ações, a menos que elas sejam claramente prejudiciais para outras pessoas" (GOLDIM, 2012, s.p.), como defende Mill.

Para Gaille (2010, p. 47, tradução livre), percebe-se uma expressão contemporânea dessa concepção dentro da afirmação e a promoção pública (a partir de pontos de vista privados) de um senso da "dignidade" da pessoa humana, concorrente daquele que foi desenvolvido dentro do pensamento bioético a partir da moral kantiana ${ }^{5}$.

Em outras palavras, a concepção de Mill é uma concepção concorrente a de Kant, e que afirma, de modo diferente, que todo ser humano é, sob formas diversas, provido de um sentimento de dignidade ('um senso de dignidade') ${ }^{6}$ (GAILLE, 2010, p. 48, tradução livre).

Para Mill, desprezar a opinião do outro gera um sentimento de elevação ou de degradação da pessoa que se afirma independente. Nesse segundo sentido, a dignidade pode se perder; mais exatamente, podese passar do sentimento de ser digno para a indignidade. É nesse senso que a noção é empregada para justificar o auxílio para morrer. A morte é então perseguida como um meio de conservar essa dignidade, e de preservar a imagem (para outro e para si mesmo) de uma existência digna ${ }^{7}$ (GAILLE, 2010, p. 48, tradução livre).

Por essas diferenças, apesar de evidente a contribuição de Kant para a construção da autonomia individual e do conceito de dignidade humana, não é unânime a posição sobre adoção da concepção kantiana nos debates bioéticos. Isto se justifica, pois, para Kant, no exercício da autonomia, em que nem toda a ação é moralmente aceitável. Assim, mesmo que determinada ação não atinja terceiros, ela não será considerada justa ou boa se não respeitar a máxima universal determinada pela razão.

Sobre o tema, Schotmans (2001, p. 14) explica que Kant define o ser autônomo "como uma pessoa que orienta seus atos por leis impessoais e gerais, não reportando unicamente às suas próprias demandas e desejos". Assim, para o autor, a concepção de autonomia de Kant não é a que aparece hoje nos debates bioéticos, invocada pelos pacientes para a solução de casos polêmicos, como a eutanásia, por exemplo. Isso porque Kant reserva o atributo da autonomia somente às decisões baseadas em razão pura.

A autonomia kantiana estabelece limites às ações do indivíduo contra si próprio, pois, como explica Gaille (2010, p. 47, tradução livre), Kant não pensa a pessoa independentemente de seu corpo. Portanto, a noção de dignidade tem implicações originais dirigidas ao sujeito do corpo: nós temos deveres para com o outro, mas também para com nós mesmos, e notadamente o de não atentar contra a nossa vida e de não degradar nosso corpo ${ }^{8}$.

Schotmans (2001, p. 14) ressalta que o conceito de autonomia, nesses casos, está mais próximo daquele desenvolvido por Mill, "o que, justificaria, segundo essa perspectiva, o critério da incurabilidade de uma doença como condição para assistência médica para a morte". Visto que Mill defende que o homem é livre para determinar o seu próprio destino, tendo como único limite os direitos das outras pessoas.

5 "On perçoit une expression contemporaine de cette conception dans l'affirmattion et la promotion publique (à partir de points de vue privés ou associatifs) d'un sens de la 'dignité' de la personne humaine, concurrent de celui que l'on a développé dans la pensée bioéthique à partir de la morale kantienne" (GAILLE, 2010, p. 47).

6 "J.S. Mill, chez qui l'on rencontre une conception concurrente de celle de Kant, affirme de façon différente que tout être humain est, sous des formes diverses, porvu d'un sentiment de dignité ('a sense of dignity') (GAILLE, 2010, p. 48).

$7 \quad$ “Dans ce second sens, la dignité peut se perdre; plus exactement, on peut passer du sentiment d'être digne de soi à celui de l'indignité. C'est en ce sens que la notion est employée pour justifier la demande de laisser mourir ou l'aide pour mourir. La mort est alors perçue comme le moyen de conserver sa dignité, et preserver l'image (pour autrui et soi-même) d'une existence digne" (GAILLE, 2010, p. 48).

8 "Kant ne pense pas la personne indépendemment de son corps. De ce fait, la notion de dignité a des implications originales directes au sujet du corps: nous avons des devoirs envers autrui, mais aussi envers nous-mêmes, et notamment celui de ne pas attenter à notre vie et de ne pas 'degrader' notre corps'. (GAILLE, 2010, p. 47). 
Mill defende que o controle social sobre as ações individuais é legitimado somente se for necessário prevenir danos para outros indivíduos, sendo que as pessoas deveriam ter permissão para desenvolver suas potencialidades de acordo com suas próprias convicções. Ele acredita que uma pessoa, com um verdadeiro caráter, é genuinamente individual, enquanto que uma pessoa "sem caráter" está sob o controle de influências da Igreja, do Estado, do país ou da família" (COHEN; MARCOLINO, 2002, p. 87).

Assim, pode-se afirmar que a autonomia como autodeterminação é apenas uma das possíveis leituras da autonomia hoje, pois "[...] a inclusão do outro na questão da autonomia trouxe, desde o pensamento de Kant, uma nova perspectiva que alia a ação individual com o componente social. Desta perspectiva que surge a responsabilidade pelo respeito à pessoa, que talvez seja a melhor denominação para este princípio" (GOLDIM, 2012, s.p.).

O limite imposto pelo componente social à ação individual serve, em Kant, para estabelecer a máxima universal que deverá ser observada nas decisões consideradas boas em si mesmas, determinadas a priori pela razão. Sob essa concepção, qualquer ação direcionada a si próprio é classificada como justa e boa se considerar o que seria bom para coletividade, e não para o sujeito autônomo que está decidindo.

Nesse sentido, Habermas (2004, p. 5-6) destaca que a teoria moral é guiada pela dúvida que o homem tem sobre o que deve ser feito. Explica que a noção de dever toma outro significado quando a questão deixa de ser feita sob "uma perspectiva inclusiva do 'nós', e passa a ser feita sob a perspectiva da primeira pessoa, uu seja, se a pessoa questiona "qual a melhor coisa a fazer 'por mim' ou 'por nós' a longo prazo, observando-se o todo".

Habermas (2004, p. 6), apesar de destacar a importância da teoria kantiana para a definição da autonomia, por outro lado, aponta o ponto fraco da autonomia kantiana para aplicação na atualidade. $\mathrm{O}$ autor explica que as respostas às questões acima destacadas só são possíveis em determinado contexto de vida. Segundo o autor, para essas questões não existe uma "resposta universal e igualmente definitiva para todas as pessoas".

Para Habermas (2004, p. 7), "teorias deontológicas após Kant ainda poderiam explicar muito bem como as normas morais devem ser fundamentadas e aplicadas; no entanto, elas não são capazes de responder por que efetivamente devemos ser morais", pois falta a "motivação para converter em prática os argumentos morais" (HABERMAS, 2004, p. 11). Em suma, sobre o atual conceito de autonomia, Habermas (2004, p. 48) esclarece:

Em sua versão destranscendentalizada, a 'vontade livre' de Kant não cai mais do céu como uma característica de seres inteligíveis. A autonomia é, antes, uma conquista precária de existências finitas, que só conseguem 'se fortalecer' quando conscientes de sua vulnerabilidade física e de sua dependência social. Se este for o 'fundamento' da moral, então seus limites se explicam a partir dele. É o universo das relações e interações interpessoais possíveis, que necessita e é capaz de impor regras morais. Apenas nessa rede de relações de reconhecimento legitimamente reguladas é que as pessoas podem se desenvolver e manter uma identidade pessoal, junto com sua integridade física.

Portanto, a máxima definida a priori pela razão não é suficiente hoje para limitar o exercício da autonomia. Pode-se afirmar que atualmente são elementos indispensáveis ao exercício da autonomia: a liberdade de escolha entre as opções possíveis e a capacidade para avaliação dos riscos e consequências da opção.

Nessa linha, defendem Cohen e Marcolino (2002, p. 85) que "a autonomia será apenas realizável quando existirem elementos racionais e emocionais de opção, ou seja, se houver liberdade face a esse conflito (entre emoção e razão)".

Assim, a concepção de autonomia afasta-se da noção kantiana (cujos limites são estabelecidos exclusivamente pela razão), para ter como limites, além do elemento racional, a possibilidade do indivíduo 
de decidir com base na sua experiência de vida e em outras circunstâncias que limitam as possibilidades existentes.

A liberdade reconhecida como possibilidade ao exercício da autonomia, nesse caso, não é incondicionada ou ilimitada, ela se dá dentro de possibilidades finitas, estabelecidas de acordo com a motivação e dependente da capacidade para exercê-la, servindo a justa medida como critério "de uma eleição entre possibilidades determinadas e condicionantes" (COHEN; MARCOLINO, 2002, p. 86). Em outras palavras, uma limitação que considera as condições que a realidade impõe ao homem, sem ser infalivelmente previsível (COHEN; MARCOLINO, 2002, p. 86).

\section{O testamento vital como instrumento para o exercício da autonomia sobre o próprio corpo}

O debate sobre os limites da autonomia sobre si mesmo tem sido frequente quando se aborda o tema testamento vital. $O$ respeito à autonomia da pessoa, diante dos novos recursos tecnológicos que permitem prolongar a vida (ou o sofrimento) do paciente em estado terminal, sem benefícios, é um dos fundamentos que justificam a elaboração de um documento que vincule a decisão médica à decisão do próprio paciente sobre a aceitação ou rejeição de procedimentos terapêuticos.

O apelo ao reconhecimento do direito de morrer com dignidade tem merecido a atenção dos juristas face ao cenário que acompanha o contexto de fim de vida nos hospitais e clínicas, que é, muitas vezes, desolador. Esse fato se deve a vários fatores que podem ser modificados pelo reconhecimento do paciente como pessoa, com sua história de vida, experiências e conhecimentos, sua liberdade e seus condicionamentos (BRAUNER, 2010, p. 183).

No Brasil ainda não existe lei dispondo sobre o tema, apenas normas éticas previstas na Resolução $\mathrm{n}^{\circ} 1.995$ de 2012, emitida pelo Conselho Federal de Medicina. O objetivo dessa normativa é de possibilitar ao paciente estabelecer "diretivas antecipadas de vontade", que podem ser definidas como "[...] o conjunto de desejos, prévia e expressamente manifestados pelo paciente, sobre cuidados e tratamentos que quer, ou não, receber no momento em que estiver incapacitado de expressar, livre e autonomamente, sua vontade" (Artigo 1, Resolução 1995, CFM, 2012).

Essa decisão sobre tratamento futuro pode ser expressa por meio de procurador ou de testamento vital, que é um documento para manifestação de vontade prévia do paciente sobre seu desejo de rejeição, ou suspensão, de tratamentos médicos que eventualmente sejam recomendados em razão de estado de terminalidade ou doença incurável.

Nesse sentido, é importante destacar, como faz Dadalto (2015, p. 35), que o testamento vital se aplica somente aos casos que retiram do paciente a possibilidade de decidir sobre o tratamento, e que envolvam doenças incuráveis e incapacitantes.

O documento deverá observar quanto ao seu conteúdo, limites éticos estabelecidos pelos princípios da bioética e do biodireito, além dos limites estabelecidos pelos direitos fundamentais e de personalidade. Ademais, deverá observar regras relativas à capacidade e forma para que sua validade não seja prejudicada, e a publicidade para que não seja ineficaz. ${ }^{9}$

Os desejos manifestados no referido documento devem ser levados em consideração pelo médico, desde que estejam de acordo com as regras estabelecidas no Código de Ética Médica (Resolução 1995, CFM, 2012). Portanto o exercício da autonomia não é ilimitado, devendo o paciente decidir dentro dos

9 A análise desses requisitos não cabe nos limites deste trabalho, que tem o objetivo de destacar apenas, que o Testamento Vital é um instrumento que é reconhecido para garantir o exercício da autonomia pelo paciente, antecipando sua decisão sobre limites terapêuticos. 
limites estabelecidos em nosso ordenamento jurídico, notadamente com base no respeito à dignidade humana e nos direitos de personalidade.

Não são válidas, por exemplo, disposições relativas à eutanásia, pois, segundo o disposto no artigo 41 do Código de Ética Médica, é vedado "abreviar a vida do paciente, ainda que a pedido deste ou de seu representante legal". O Código prevê, ainda, o dever do médico de oferecer tratamentos disponíveis "sem empreender ações diagnósticas ou terapêuticas inúteis ou obstinadas, levando sempre em consideração a vontade expressa do paciente ou, na sua impossibilidade, a de seu representante legal".

Por outro lado, a ortotanásia é admitida, como já decidiu o Tribunal de Justiça do Rio Grande do Sul, ao reconhecer, com base no direito à vida com dignidade, a aplicação do testamento vital:

\begin{abstract}
APELAÇÃO CÍVEL. ASSISTÊNCIA À SAÚdE. BIODIREITO. ORTOTANÁSIA. TESTAMENTO VITAL. 1. Se o paciente, com o pé esquerdo necrosado, se nega à amputação, preferindo, conforme laudo psicológico, morrer para 'aliviar o sofrimento'; e, conforme laudo psiquiátrico, se encontra em pleno gozo das faculdades mentais, o Estado não pode invadir seu corpo e realizar a cirurgia mutilatória contra a sua vontade, mesmo que seja pelo motivo nobre de salvar sua vida. 2 . O caso se insere no denominado biodireito, na dimensão da ortotanásia, que vem a ser a morte no seu devido tempo, sem prolongar a vida por meios artificiais, ou além do que seria o processo natural. 3. O direito à vida garantido no art. $5^{\circ}$, caput, deve ser combinado com o princípio da dignidade da pessoa, previsto no art. $2^{\circ}$, III, ambos da CF, isto é, vida com dignidade ou razoável qualidade. A Constituição institui o direito à vida, não o dever à vida, razão pela qual não se admite que o paciente seja obrigado a se submeter a tratamento ou cirurgia, máxime quando mutilatória. Ademais, na esfera infraconstitucional, o fato de o art. 15 do CC proibir tratamento médico ou intervenção cirúrgica quando há risco de vida, não quer dizer que, não havendo risco, ou mesmo quando para salvar a vida, a pessoa pode ser constrangida a tal. 4. Nas circunstâncias, a fim de preservar o médico de eventual acusação de terceiros, tem-se que o paciente, pelo quanto consta nos autos, fez o denominado testamento vital, que figura na Resolução n 1995/2012, do Conselho Federal de Medicina. 5. Apelação desprovida. (Apelação Cível Nº 70054988266, Primeira Câmara Cível, Tribunal de Justiça do RS, Relator: Irineu Mariani, Julgado em 20/11/2013).
\end{abstract}

Inexistindo diretivas antecipadas de vontade do paciente, ou mandato especial para que alguém decida sobre tais questões, caberá aos familiares ou ao Comitê de Bioética ou Comissão de Ética Médica do hospital ou, ainda, ao Conselho Regional e Federal de Medicina a decisão sobre conflitos éticos, quando entender esta medida necessária e conveniente (RESOLUÇÃO n. 1995, CFM, 2012). Em outras palavras, o consentimento é necessário, e será suprido por terceiros quando o paciente não tiver mais capacidade de manifestação livre ou não tiver deixado procurador especial, ou testamento vital.

A manifestação de vontade do paciente deve prevalecer, com fundamento na dignidade e na autonomia do paciente. Contudo, dependendo da concepção de autonomia adotada, mesmo dentro dos limites estabelecidos pelas normas éticas citadas, poderia se alegar que o testamento vital envolve 0 direito indisponível à vida, o que fundamentaria sua rejeição (autonomia kantiana) ou que, sendo soberano, o paciente tem o direito a decidir pela abreviação da vida, rejeitando tratamentos inúteis e dolorosos, reflexão essa fundamentada na concepção de autonomia de Mill.

\title{
7 Conclusão
}

$\mathrm{Na}$ atualidade, o que determina o justo limite da autonomia do indivíduo sobre si mesmo é a máxima universal apriorística defendida por Kant, ou a liberdade baseada na experiência pessoal de cada um, defendida por Mill?

No presente texto foi possível destacar a importância de ambas as teorias para o desenvolvimento da noção atual sobre a autonomia. Elas são utilizadas como base para fundamentar o respeito ao direito que todo homem capaz tem de decidir sobre seu corpo e sua vida, que se confunde com o respeito à dignidade humana e à própria pessoa. 
Autonomia, hoje, especialmente nos debates bioéticos, não se confunde com simples liberdade ou autodeterminação, mas uma característica indissociável da pessoa, condição de sua dignidade. Todavia, o exercício desse direito pode ser prejudicial, quando movido por fortes emoções e sentimentos, ou quando quem decide é mal informado sobre as possíveis consequências da sua decisão. Assim, reconhecese a importância da imposição de limites ao exercício da autonomia, contudo esses limites devem ser devidamente justificados e avaliados com base nas circunstâncias e possibilidades para cada caso.

São polêmicos os debates sobre a possibilidade de exercício dessa autonomia para a prática de ações extremas, como a supressão da própria vida, no caso da eutanásia, por exemplo. Questiona-se se existe moralidade quando se considera apenas o próprio ponto de vista, a dor, e os sentimentos daquele que invoca a autonomia para decidir sobre o fim da sua vida. Para tanto, novamente são invocadas as concepções analisadas.

Sob a perspectiva da autonomia kantiana, a manifestação de vontade em testamento vital envolve um direito supremo e indisponível: a vida. Para Kant, viver apresenta-se mais como um dever, e não como um direito. A adoção dessa concepção afasta a possibilidade de decidir sobre o fim da vida, decisão que não seria justa em consideração a uma moral universal.

A autonomia kantiana não justifica esse tipo de decisão, porque decidir pelo fim da própria vida não pode ser uma máxima válida universalmente. Ademais, essa seria uma ação que não é boa em si mesma, mas que é realizada com o intuito de evitar o sofrimento. O homem é um fim em si mesmo, não podendo agir visando a outro fim, movido por impulsos ou emoções, esse agir é heterônomo, e não autônomo, portanto a autonomia kantiana não pode fundamentar essas ações, e apresenta-se como um obstáculo ao invocado "direito de morrer".

Por outro lado, analisado sob a perspectiva da autonomia de Mill, o testamento vital apresenta-se como um instrumento hábil para o exercício da autonomia fundamentada na soberania sobre o próprio corpo e mente e à própria vida, que poderia ser prejudicado se não fosse possibilitado de forma prévia, ou seja, a vontade do paciente deve prevalecer sobre qualquer decisão médica ou de familiares, pois o atendimento às diretivas antecipadas de vontade significa o respeito à autonomia e dignidade do paciente.

No que diz respeito aos impulsos e desejos, que poderiam influenciar a decisão, é importante destacar que a capacidade exigida para a validade da manifestação de vontade externada via testamento vital, e o momento da elaboração do documento, devam garantir que esses sentimentos não interfiram na decisão do paciente, pois se trata de diretiva antecipada da vontade, e não uma decisão tomada em um momento de dor.

Importante destacar ainda que os limites estabelecidos para o testamento vital, em nosso ordenamento jurídico proíbem a interferência ativa sobre o processo vital (eutanásia), afastando os argumentos da concepção kantiana de que seria uma ação injusta e um ato egoísta de atentar contra a própria vida por amor a si mesmo.

A vida não pode ser imposta como dever, afastando de forma geral a possibilidade de decisão sobre o processo vital. Ademais, no Brasil, apesar da decisão manifestada em testamento vital possivelmente refletir na abreviação da vida, tal opção pela ortotanásia representa justamente a rejeição à interferência no processo vital, impedindo que a vida seja prolongada artificialmente.

Diante disso, vale dizer que o respeito à autonomia e à dignidade do paciente está no respeito a sua decisão manifestada em testamento vital. Nesse sentido, o testamento vital não se funda no critério de universalidade da autonomia kantiana, mas na autonomia que decorre do respeito à dignidade do paciente.

Respeitar a pessoa e a sua dignidade, nessa perspectiva, significa não impedir a ação pensada, desejada e devidamente fundamentada na sua experiência de vida, na sua dor e na concepção sobre vida digna. 
Seria a partir desses argumentos que a concepção de autonomia de Stuart Mill fundamentaria a não imposição de limites às ações do indivíduo sobre si mesmo, pois a experiência própria legitima a pessoa a tomar decisões que não prejudiquem terceiros, podendo, portanto, deliberar livremente sobre a própria vida e o próprio corpo, em decorrência da dignidade que Ihe é reconhecida. Para Mill, o homem é senhor do próprio destino, e delegar a outrem a decisão sobre a própria vida é desconsiderar a dignidade da pessoa. Assim, a autonomia de Mill fundamentaria o direito de toda a pessoa nas ações direcionadas a si mesmo e o testamento vital consistiria em um adequado instrumento para o exercício dessas ações.

\section{Referências}

ARISTÓTELES. Ética a Nicômaco. Tradução de Torrieri Guimarães. São Paulo: Martin Claret, 2009.

BARRETTO, Vicente. $O$ fetiche dos direitos humanos e outros temas. Rio de Janeiro: Lumen Juris, 2010.

BRAUNER, Maria Claudia Crespo. As intermitências da vida: obstinação terapêutica e a defesa do direito de morrer com dignidade. In: LIMA, Taisa Macena de; SÁ, Maria de Fátima Freire de; MOUREIRA, Diogo Luna (Org.). Direitos fundamentais entre a vida e a morte. Rio de Janeiro: Lumen Juris, 2010. p. 181189.

BARRETTO, Vicente. A ideia de pessoa humana e os limites da bioética. In: BARBOZA, Heloisa Helena; BARRETTO, Vicente de Paulo (Org.). Novos temas de biodireito e bioética. Rio de Janeiro: Renovar, 2003.

CHAVES, Eduardo O. C. David Hume e a questão básica da crítica da razão prática. Disponível em: <http://www.cfh.ufsc.br/ wfil/hume2.htm>. Acesso em: 7 abr. 2012.

COHEN, Cláudio; MARCOLINO, José Álvaro M. Relação médico-paciente: Autonomia \& paternalismo. In: SEGRE, Marcos; COHEN, Cláudio (Org.). Bioética. 3. ed. rev. e ampl. São Paulo: Edusp, 2002. p. 53-38.

CONSELHO FEDERAL DE MEDICINA. Código de Ética Médica. 13 abril 2010. Disponível em: < http:// www.aborlccf.org.br/imageBank/NOVO_CODIGO_ETICA_MEDICA.pdf> Acesso em: 12 maio 2012.

CONSELHO FEDERAL DE MEDICINA. Resolução n. 1995, de 2012. Disponível em: <http://www. portalmedico.org.br/resolucoes/CFM/2012/1995_2012.pdf >. Acesso em: 12 set. 2012

DADALTO, Luciana. Testamento vital. 3. ed. São Paulo: Atlas, 2015.

GAILLE, Marie. La valeur de la vie. Paris: Les Belles Lettres, 2010.

GARRAFA, Volnei. Respeito à autonomia e livre consentimento em pesquisas com material biológico armazenado. Revista da Associação Médica Brasileira, São Paulo, v. 56, n. 5, p. 494-495, 2010. Disponível em: <http://www.scielo.br/scielo.php?pid=S0104-42302010000500001\&script=sci_arttext>. Acesso em: 12 maio 2012.

GOLDIM, José Roberto. Princípio do respeito à pessoa ou autonomia. Bioética. Porto Alegre. 2004. Disponível em: <http://www.bioetica.ufrgs.br/autonomi.htm>. Acesso em: 17 mar. 2012.

HABERMAS, Jürgen. O futuro da natureza humana. São Paulo: Martins Fontes, 2004.

HÖFFE, Otfried. Immanuel Kant. Tradução de Christian Viktor Hamm e Valeri Rohden. São Paulo: Martins Fontes, 2005.

KANT, Immanuel. Crítica da razão pura. Tradução de Alex Marins. São Paulo: Martin Claret, 2004a.

KANT, Immanuel. Fundamentação da metafísica dos costumes e outros escritos. Tradução de Leopoldo Holzbach. São Paulo: Martin Claret, 2004b.

KANT, Immanuel. A religião nos limites da simples razão. Tradução: Ciro Mioranza. São Paulo: Escala Educacional, 2006.

MILL, Stuart. Sobre a liberdade. Tradução: Ari R. Tank Brito. São Paulo: Hedra, 2011. 
NOUR, Soraya. Autonomia. In: BARRETTO, Vicente de Paulo (Coord.) Dicionário de Filosofia do Direito. São Leopoldo/ Rio de Janeiro: Unisinos/Renovar, 2009.

ROHDEN, Valério. Uma ética realizada pelo desejo de realização da humanidade. In: Emmanuel Kant: razão, liberdade, lógica e ética. Cadernos IHU em formação, São Leopoldo, Unisinos, ano 1, n. 2, 2005. Disponível em: <http://www.ihu.unisinos.br/images/stories/cadernos/formacao/002cadernosihuemformac ao.pdf>. Acesso em: 15 abr. 2012.

ROSSEAU, Jean-Jacques. O contrato social. Tradução: Ciro Mioranza. São Paulo: Escala, [s.d.].

SARLET, Ingo Wolfgang. Dignidade da pessoa humana e direitos fundamentais na constituição federal de 1988. 2. ed. Porto Alegre: Livraria do Advogado, 2002.

SCHOTMANS, Paul. T. O homem como criador? Desenvolvimentos na genética humana e os limites da autodeterminação humana. Cadernos Adenauer, Rio de Janeiro, ano III, n.1, p. 13-16, maio, 2002.

SELETTI, Jean Carlos; GARRAFA, Volnei. As raízes cristãs da autonomia. Petrópolis: Vozes, 2005.

SIMÕES, Mauro Cardoso. Liberdade e paternalismo segundo John Stuart Mill: uma análise das teses de on liberty. 2007. 161 f. Tese (Doutorado em Filosofia) - Universidade Estadual de Campinas, São Paulo, 2007.

TAYLOR, Charles. As fontes do self: a construção da identidade moderna. Tradução de Adail Ubirajara Sobral e Dinah de Abreu Azevedo. São Paulo: Loyola, 2011.

Recebido em: 16/07/2015

Aprovado em: 10/11/2015 